\title{
Towards realizing robotic potential in future intelligent food manufacturing systems
}

\author{
Zeashan Hameed Khan ${ }^{\mathrm{a},}{ }^{*}$, Azfar Khalid $^{\mathrm{b}}$, Jamshed Iqbal ${ }^{\mathrm{c}}$ \\ ${ }^{\mathrm{a}}$ Department of Electrical Engineering, Bahria University, Islamabad, Pakistan \\ ${ }^{b}$ Department of Mechanical Engineering, Capital University of Science \& Technology, \\ (CUST) Islamabad, Pakistan \\ ${ }^{c}$ Department of Electrical and Computer Engineering, University of Jeddah, Saudi Arabia \\ *Corresponding author: zhameed.buic@bahria.edu.pk
}

\begin{abstract}
:
This paper provides a comprehensive review of the robotic potential that is forseen by researchers in designing future food manufacturing plant. The present day food handling and packaging setup is limited in capacity and output due to manual processing. An optimized protocol to fetch various ingrediants and shape them in a final product by passing through various stages in an automated processing plant while simultaneously ensuring high quality and hygienic environment is merely possible by using robotized processing. The review also highlights the possibilities and limitations of introducing these high technology robots in the food sector. A comparison of several robots from different classes is listed with major technical parameters. However, as predicted, a food cyber-physical production system (CPPS) visualizes a closed loop system for the desired output keeping in view various constraints and risks. Human machine interface (HMI) for these machines complies with the industrial safety standards to provide a fail safe production cycle. Various new horizons in research and development of food robots are also highlighted in the upcomping industrial paradigm.
\end{abstract}

Key words: Robotics in food industry; Cyber physical systems; Food handling and processing robotics; Food serving robotics.

\section{Introduction}

In an industrial perspective, automation deals with electrical/electronic, mechanical and computer-based solutions to operate and control the production processes. In view of that, the field of robotics belongs to the class of industrial automation [1]. Pressing demands of improved and enhanced productivity in industrial applications have compelled the placement of robots to automate various tasks [2]. Today, robots are highly automated mechanical manipulators controlled by computers. Robots are now considered as an integral part of industries due to their role in improving accuracy, repeatability, reliability, preciseness and efficiency [3]. Use of robots helps to eliminate injuries, improve production frequency and quality, reduce direct labour costs and augments safety [4]. Industrial robots, usually composed of a manipulator-like articulated structure [5], can be programmed to move its links and end-effector through a sequence of motions in order to perform some 
useful task [6]. It will repeat that motion pattern over and over until reprogrammed to perform some other task.

Generally, the population of industrial robots is observed to show an increasing trend. Figure 1 presents an estimated operational stock of industrial robots from 20122017. The trend of industrial robot's growth of 2013 is anticipated to be continued in near future as evident from the figure.

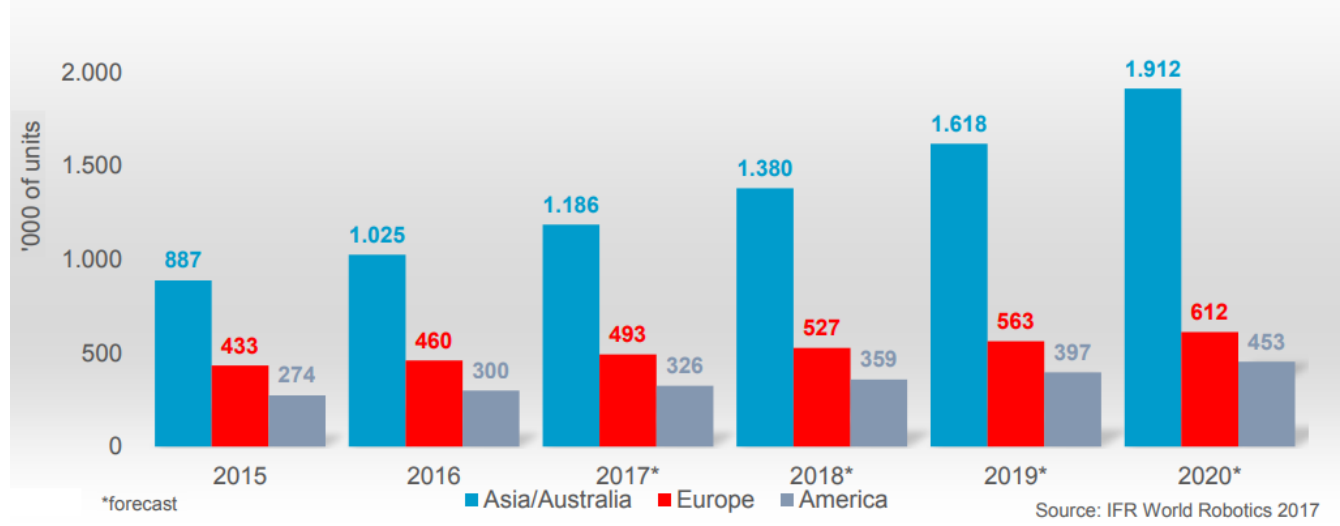

Figure 1. Operational stock of industrial robots (2015-16) and forecast for (2017-20) [7]

Previously, the robots were primarily used in the packaging of food and palletizing in sub-domains of food industry e.g. dairy, beverages, chocolates and food tins. The scenario changed with the launch of the Flex-Picker from ABB in 1998 which revolutionized the food industry being the fastest pick and place robot of the world. The light weight applications started since then for food processing and even meeting the extreme hygienic conditions. The list of potential benefits achieved are the reduction in material movements and vehicle activity, improved operational efficiency as well as a signifant reduction in-process stages [8].

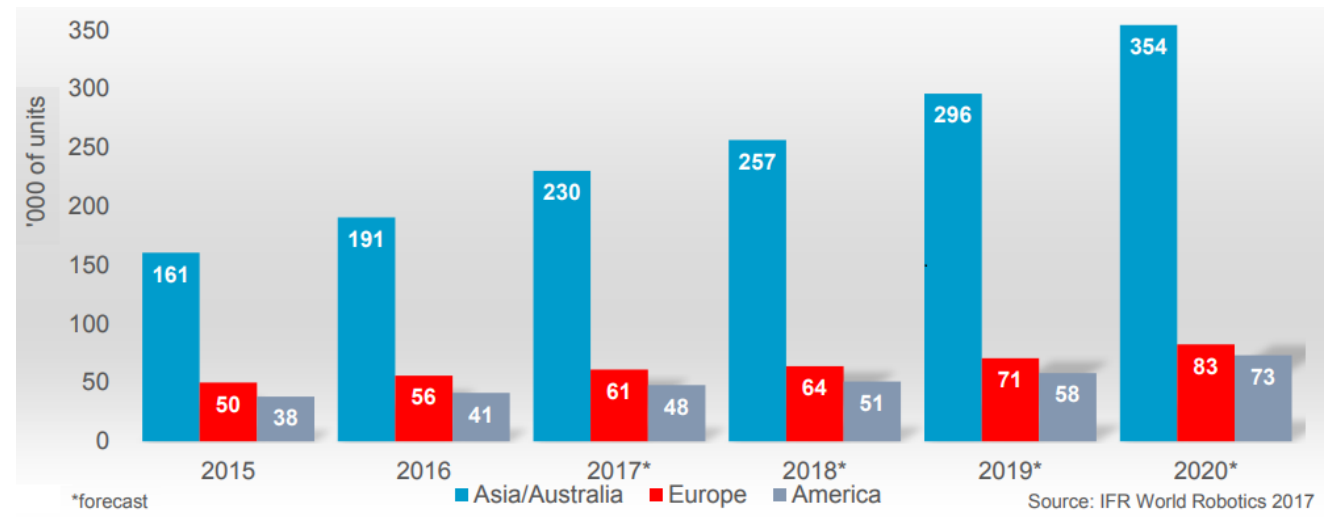

Figure 2. Worldwide supply of industrial robots (2015-16) and forecast (2017-20) [7]

Present day food processing plants are using automation solutions which are cost effective for higher production volume as compared to the conventional processes [9]. As the dependence on manual labor is deemed as a classical concept in today's industrial processes, more preference is given to robotized handling/manufacturing installations [10]. Most common examples include; picking and placing, packaging and palletizing applications which are considered to have a bulk potential in the future food industry [11]. Fig. 2 shows an upward trend in utilization of robots in packaging lines. According to 2015 executive summary of World Robotics, year 2015 witnessed 
$27 \%$ increase in robot orders for food and beverage industry. With almost 7,100 deployed units (Fig. 3), this accounts for a share of $4 \%$ of the total supply of industrial robots.

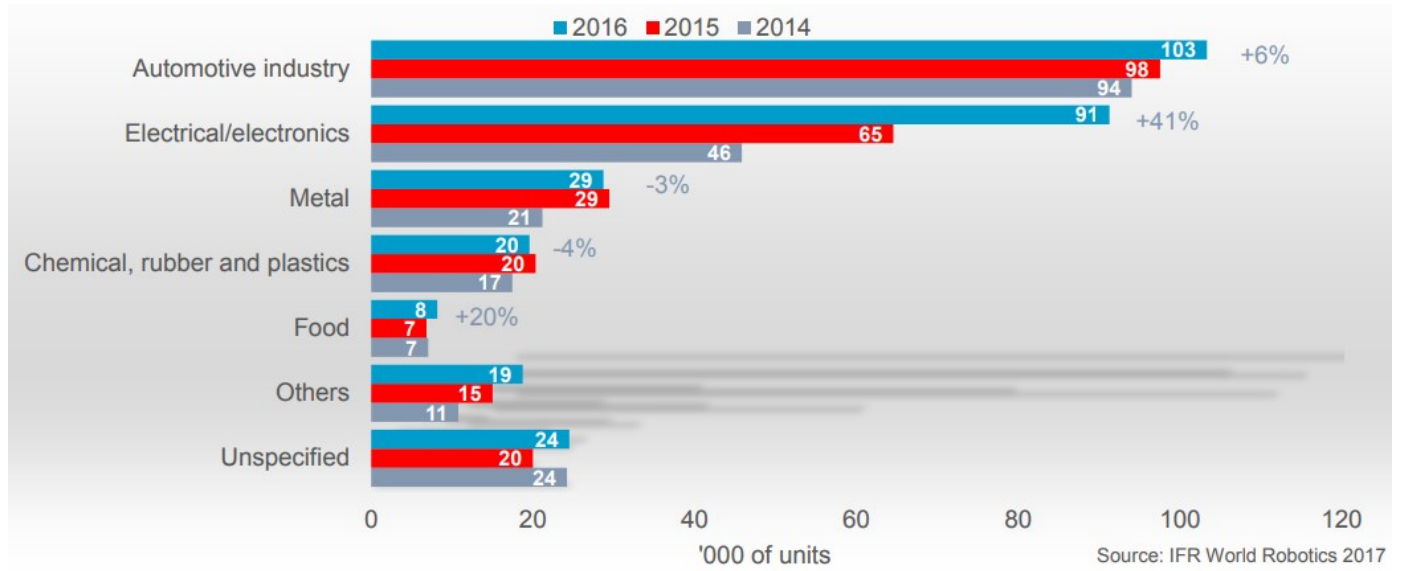

Figure 3. Estimated worldwide annual supply of robots for food and other industrial sectors

(2014-2016) [7]

In agriculture and food industry, robots are being used in every task i.e. from seeding, spraying water and harvesting to cutting, processing and packaging of food products [12]. Various robot systems are used in automatic quality detection of the final product of bakery items [13] as well as in meat processing [14] (See Fig. 4). Moreover, in beverages industry, robotic machines are used in cleaning bottles, counting, filling and arranging on a conveyer belt automatically. In addition to that, for defect identification and inspection through robot learning, multiple High Definition (HD) cameras are utilized [15]. Another application is the use of multiple spectrum cameras for farming industry where the micro Unmanned Aerial Vehicles $(\mu \mathrm{UAV})$ are the platform carriers [16-18]. The aerial surveys are conducted to estimate forest area and crop fields for calculation of the biomass and forest inventory in different countries of the world [19].

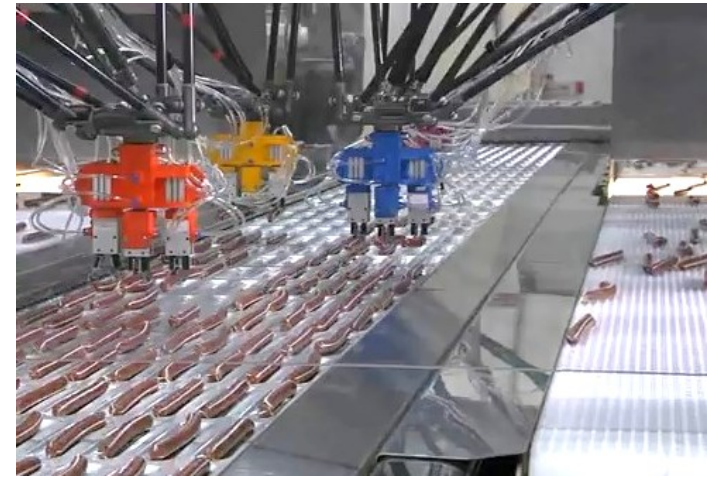

(a)

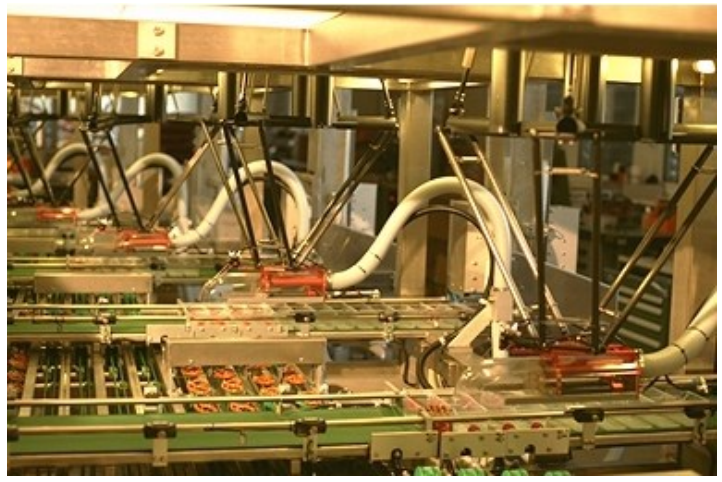

(b)

Figure 4. Food packaging lines using ABB's FlexPicker [20] (a) Three industrial robots sorting and placing salami of the mini pepperoni. (b) Parallel robots for the packaging of pretzels in an industrial bakery

In today's competitive industrialization regime, one can witness a number of key food processing companies and manufacturers of packaging machinery who have successfully integrated robots in many different processes including dairy, poultry, baking, confection, frozen food, snacks and beverages to name few [21]. Some of 
these applications are unique patented inventions which exploit the flexibility of robots, but more typically a robot is deployed to complement a traditional packaging machine [22]. It is important to note that the food industry is still a new market for robots because standardization for safety and hygienic processing is not trivial. Special reference is made to poultry and meat industry where e.g. chicken and fish fillets or lettuces, vary in quality and size [23]. Moreover, in the slaughter and meat processing industries, there is growing automation, e.g. robotic carcass splitters and hide pullers, which increase the production without occupying much space as compared to manual operation [24].

This paper presents a broad assessment of the technological parameters in robotics which are vital for the future of food processing technology in the context of industry 4.0's viewpoint. As Section 1 has introduced the fundamental issue pertaining to increased use of robot in the food processing industry, Section 2 covers the general requirements, robot structural configurations and guidelines that are used to convert a commercially available robot to be useable in food industry environment. Section 3 classifies the robots used in food industry w.r.t. kinematics and applications. Section 4 elaborates the challenges and further opportunities in terms of the growing technological demands in this important industrial sector. Section 5 comments on the conclusions and highlights the potential benefits of robots deployment in food industry.

\section{Requirements in Food Industry}

In order to add robotic technology in the present-day food industry, a detailed analysis of requirements is necessary. These requirements are studied from various aspects including kinematics, dynamics, hygiene, productivity, worker safety, cost and ease of operation and maintenance [8].

\subsection{Kinematics and dynamics}

Robots are majorly characterized as stationary/mobile robots, industrial robots, service robots and harvesting robots. Robots used in food industry can be kinematically based on serial or parallel mechanisms. The requirements in food industry is mostly fulfilled by the serial robots in which all the axes are stacked one over the other. In fact, these are traditional robots usually articulated vertically. Parallel robots is the second most favourite class used in the food industry and is currently more common [25]. (See Figure 5)

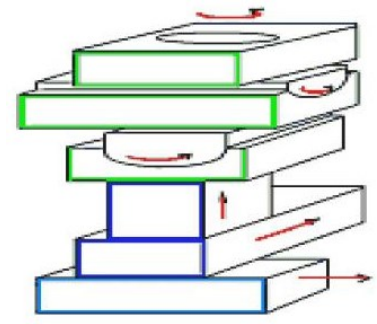

(a)

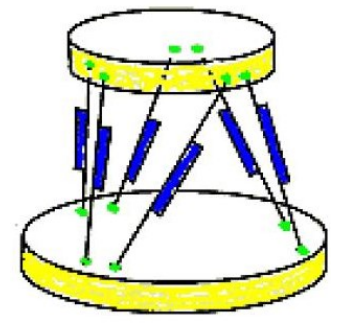

(b)

Figure 5. Robot categories (a) Serial stage (b) Parallel kinematic manipulator

An example of serial robot is AUTonomous Articulated Robotic Educational Platform (AUTAREP) manipulator, which is a novel and pseudo-industrial multiDOF framework indigenously developed for educational and research purposes. It is 
centered on a 6-DOF serial link articulated manipulator consisting of all revolute joints. The actuation system is composed of six precise DC geared servo motors while sensing system comprises of position encoders, Force Sensing Resistor (FSR) and an on-board camera. Software and hardware architectures of AUTAREP are reported in [26]. Figure 6 illustrates AUTAREP framework. Applications of the platform for common industrial tasks including sorting, pick and place are reported in [27].

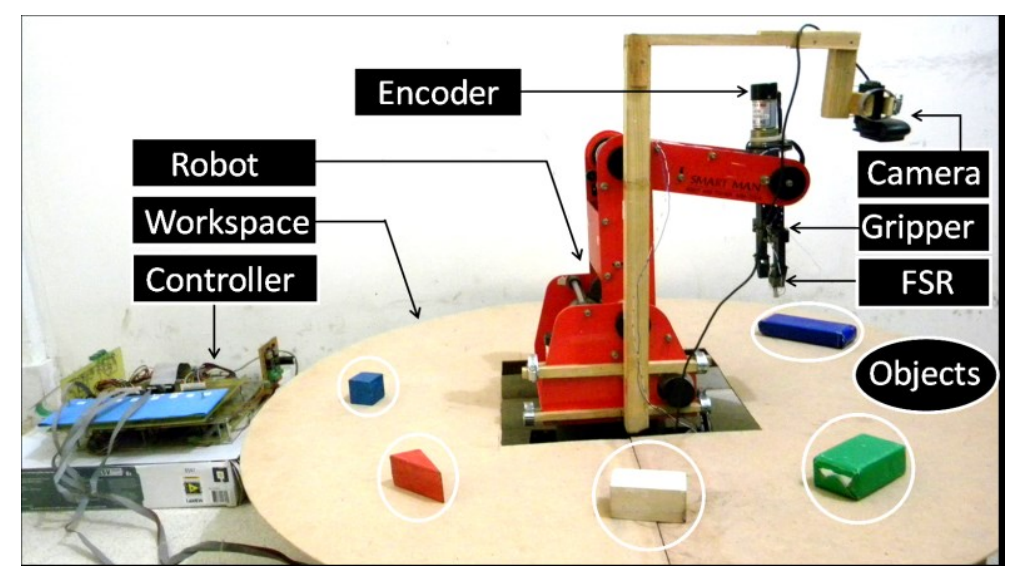

Figure 6. AUTAREP - An open source pseudo-industrial framework [27]

FlexPicker [28] is an example of Parallel Kinematic Manipulator (PKM) commonly termed as 'Delta' robot [21]. The robot is marketed by Demaurex and by ABB under the commercial name IRB340 FlexPicker. Delta [29] refers to three Degree Of Freedom (DOF) configuration which is restricted to move only in translation. Due to these characteristics, it is a natural choice for accomplishing light weight jobs and has proved itself in many applications. It is a light weight robot, initially designed for surgical application but later used extensively in food industry. PKM-based design has always the inherent ability that the end-effector possess high stiffness, low inertia with large payload capacity [30]. On the other hand, PKM has small workspace envelope where shape of the reachable workspace is symmetrical but irregular with respect to height gained by the end-effector [31].

For parallel manipulators, again the Lagrangian formulation is efficient than Newton-Euler method but the closed kinematic chain in PKM complicates the derivation of explicit equations. To solve this issue, Lin and Song [32]compared the inverse dynamics problem of closed loop system through different techniques including Newton-Euler and Lagrangian. They showed that using the principle of virtual work, a computationally efficient model can be built for analysis.

\subsection{Control and dexterity}

The study of manipulators for diversified applications has highlighted the need of sophisticated algorithms for their control and dexterity. The control of industrial manipulator is important for accomplishing tasks demanding high precision, reliability and repeatability by mitigating the effects of disturbances [33]. Trivial control approaches usually based on linear control laws like Proportional Integral Derivative (PID), Linear Quadratic Regulator (LQR) [34] and Linear Quadratic Gaussian (LQG) control [35] have been the main workhorse of industry for decades [36]. PID implementation of AUTAREP is reported in [37]. 


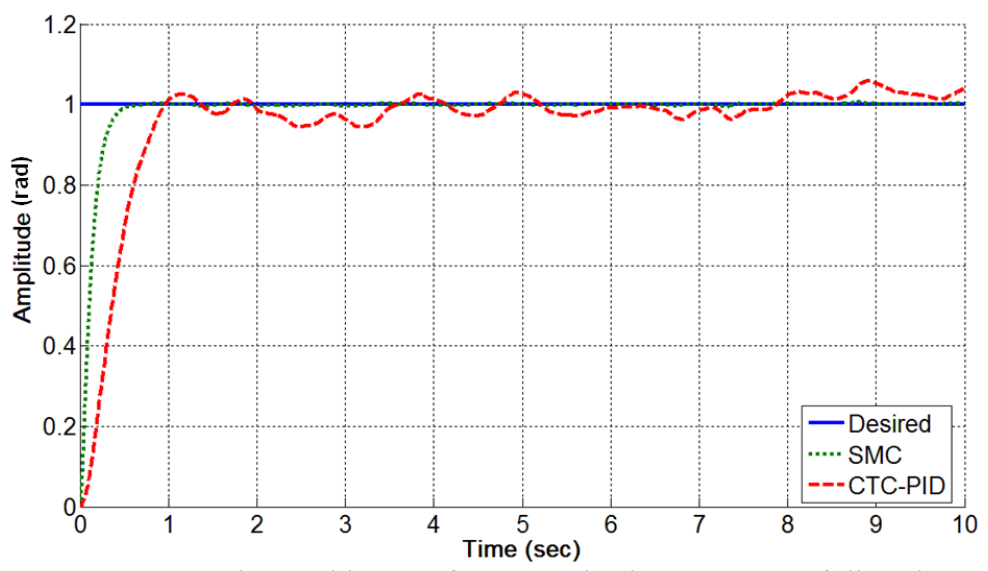

Figure 8. Comparative tacking performance in the presence of disturbances: Step responses of SMC and CTC [38]

Research community has recently applied advanced control strategies based on modern and nonlinear control laws on multi-DOF robotic manipulators. These strategies find motivation given the fact that the robotic manipulators have complex nonlinear dynamic structure with uncertainity in the model parameters and require real time control in harsh environments with noise and disturbances. Implementation of Sliding Mode Control (SMC) on AUTAREP manipulator has been reported in [39]. In the presence of disturbances, SMC overperforms than PID (Fig. 8). Recent state-ofthe-art on current and emergent control strategies for robotic manipualtors are reviewed in [40-43]. Some intelligent control schemes including artificial neural network, neuro-fuzzy control, expert system, learning control systems for robot manipulator control are also found in literature [44, 45].

While designing control and dexterity, it needs to be ensured that the sufficient DOF is allowed for the end-effector to move in all the desired axes. In PKM, it is highly desirous that the end-effector motion is highly dexterous in the reachable space envelope. But the dexterity becomes important where orientations are part of the allowable DOF. In a robot like FlexPicker, where Delta configuration or only the three translational DOF are allowed, the dexterity is not important. However, for more than three translational DOF manipulations, dexterity or orientation space calculation becomes an important task [31]. Analytical techniques for quick calculation of mobility or DOF have been reviewed by Gogu [46] for closed loop systems where it is a non-trivial problem. In comparison, serial systems are observable for DOF output by the number of arms in a robot.

There is a common misperception that robotic conversion of the product line is typically suitable for long runs of the same product. However, it has been realized very late that in fact robotics has the capacity for fastest changeover of a product if programmed according to the requirements. The software tools which robot manufacturing companies offer usually can run such simulations beforehand to determine the optimized solution. Furthermore, for faster and easy integration into existing or new lines, re-configurable feature is added in machines and robotic structures [47]. The modular design adapts better to the flexible nature of production and manufacturing.

\subsection{Hygiene}

Food cleanliness is an important issue and it can be easily ensured by food grade robots. If the food and beverage products remain untouched by humans during their processing, it is found free from the germs and bacteria. In order to satisfy such 
stringent requirements, the robotic manipulators, vision systems and specifically endeffectors or grippers require special hygienic design as an obligation in food industry [48]. The fundamental issue is that the robot should be able to work in wet environment. This can be made possible by an extensive use of stainless steel as a prime material for grippers. Another option is to use shields and seals to make the design water-proof which is practically a daunting task. The hygienic robot design must ensure that the food particles does not struck and cause bacterial growth. The specific joints near gripper are more prone to this problem. Therefore, easy to clean and easy to sterilize stainless steel revolute joints are common in the case of PKM.

Additionally, all external parts must be visible for inspection and accessible for manual cleaning. The robotic grippers used for food handling applications are washed down with industrial detergents and pressurized hot water for cleanliness [49]. Moreover, they are designed with smooth and easy to rinse-off surfaces and lubricant free joints that are resistant to most corrosives. Another feature in gripper design is its ability of food handling with moderate force such that the aesthetic requirements of food like bakery products must be met. For this, the end-effector must be able to grip soft food items without damaging them. Overall, the cleanliness and sanitation requirements are of the highest levels and their routine up keeping is vital in the food industry as seen in Fig. 9.

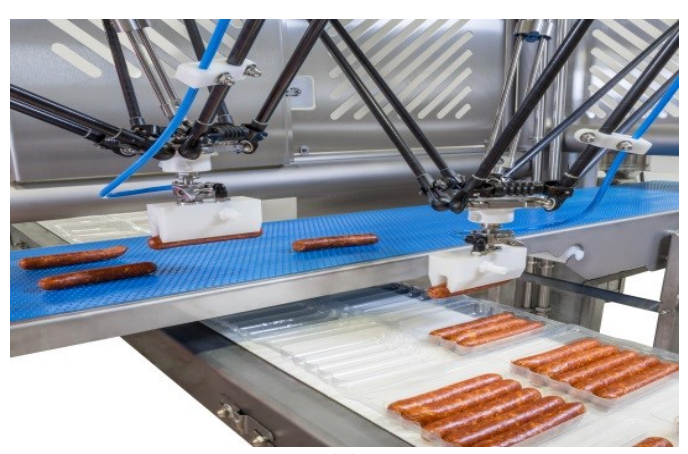

(a)

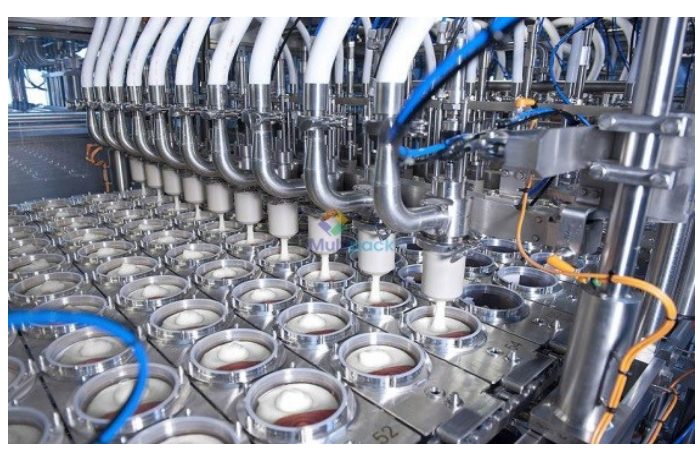

(c)

Figure 9. Food grade sterilized end-effectors are mandatory to meet certification requirements. (a) Pick and Place robot by Talon ${ }^{\mathrm{TM}}$ [50] (b) Ice-cream cup filling machine (speed 2,400 to $9000 \mathrm{pcs} / \mathrm{hr}$ with precision is $\pm 1 \%$ ) [51].

These robotic-based pick and place systems are developed with today's rigorous operational demands in mind. Moreover, these robots are designed to integrate with other packaging machinery, thus, they can easily upgrade the existing packaging lines and infrastructure to achieve a cost effective solution.

\subsection{Productivity}

There is an ever increasing trend in the productivity demand of the food preparation, handling and production. Picking and packing with high accuracy from conveyors has eliminated the need of human worker from the food production scene. This trend is increasing in the years to come which can be a threat to the worker job market. Now, the worker is introduced as a supervisor of robots and is responsible for monitoring senses data coming from various robotic setups in such environments. This situation has introduced a new specialized area of Cyber Physical System (CPS) design in which the sensor data fusion concepts are emerged. Again more specialized software e.g. Robot Studio [52] are now available for the use of such line supervisors in the case of product variation for a small amount of time. 
The food serving industry has seen its first automation in the form of the conveyor belt concept by Suchi in Japan as shown in Fig. 10. Billing is generated through the RFID chip installed at each plate [53]. Vision sensors are used for conveyor tracking and the remote observation by the human supervisors is available. Sushi is a first commercial success of automation in the food serving sector [54]. This is more of an automation approach rather than the robotic approach.

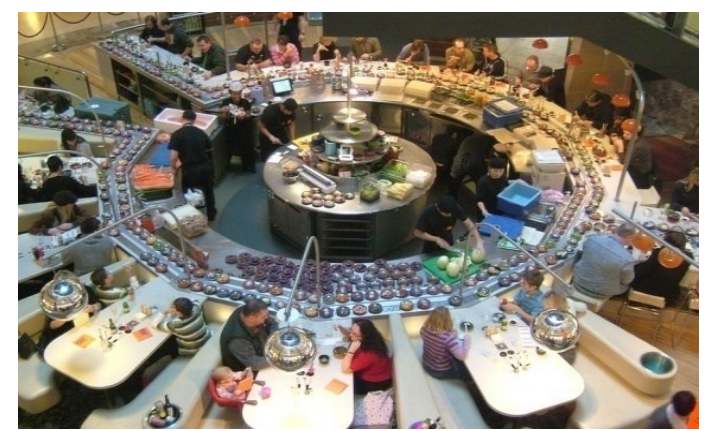

(a)

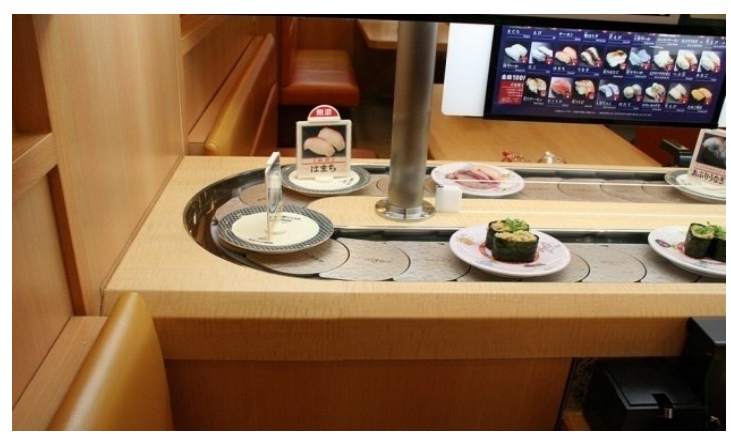

(b)

Figure 10. Robots in food serving [55] (a) Sushi serving concept through conveyor belt (b) A Sushi conveyor chain articulating around a tight corner

\subsection{Worker safety}

The dominant concept of worker safety is to completely isolate the robot system from the human worker access as shown in Fig. 9 and 10. The improvement in efficiency of industrial robots in mixed working environments is highlighted in [56]. However, the concept has technical challenges from implementation point of view. The continuous monitoring of employees working areas and of robotic systems in production through sensors is required to ensure safety. The new concepts including recording of current activities and consideration of the context and respective situation, assess the risk potential which a worker could be exposed because of the robot's movements [57]. This context-orientated system and its integration into smart production environments is the ultimate aim of the factory of tomorrow.

Other common features currently in place, in food production and serving industry, are the user friendly interfaces for recipe handling, billing and product changeover support [58]. For worker's safety in man-robot working environment, common methods employed include dual circuits with supervision, emergency stops and safety functions, 3-position enabling devices, fencing and collision detection.

\subsection{Cost}

Use of robots may offer a low cost production system in a large scale production line and may provide flexibility in the production system if the product change aspect is already covered using robotic software solutions. Hence, the benefit can shift at retail cost and up to the consumer as well. Flexible or modular designs of robots ensure fast and easy integration into existing product line [8]. Robots have also exceptionally shortened the time duration between production and delivery to a retailer, therefore, resulting in fresh supply of products.

\subsection{Ease of operation and maintenance}

Robots in food industry are always prepared for harsh and corrosive operating environments. The stainless steel parts are normally able to cope with harsh environments like cold, wet, hot, humid, corrosive to name a few. Grippers may be 
involved in routine cycle of cleaning using chemicals and detergents and then drying through hot compressed air before the food production process starts [59].

For easy operation, the robot must be of appropriate size in terms of its foot print and available workspace for reachability to accomplish required tasks. Very large foot print size is not suitable or affordable as it takes a large factory floor space. Normally, the food production factory units are smaller in size, therefore, small scale modular robotics is the most appropriate solution. Again, the human interface for reprogramming of robot configuration must be designed in order to facilitate user [60]. This may be achieved through better process control and reliable maintenance scheme designed with state of the art optimization techniques.

For ensuring reliable operation of robots and achieving the ultimate objective of avoiding discontinuity in operation of food factories, the operation needs support from the maintenance scheme. The preventive maintenance schedules are built and normally become inherent part of the robot design activity. By carrying out regular planned maintenance either manual or automated, the robotic installation can last longer by reducing costly downtime. This way, the reliability of robotic production systems can be enhanced that are easier to maintain in order to keep production idle time as minimum as possible [61].

The maintenance and repairs for Range Of Motion (ROM) of the robot while it is working to execute required operations is a recent concept. In fact, it is a very difficult scenario that the necessary work done by the robot is in place while the maintenance is underway. The concept completely deviates from the traditional scenario of robot decommissioning for maintenance. The ultimate objective of this type of robot is to respond to the new protection principle and also the robot must be able to respond appropriately and intelligently in the presence of the human worker.

Better reliability also depends on the industrial protection (IP) class selected for the robotic system. The software architectures, communication and interoperability standards can be re-used as much as possible. The objective should be to keep the new protection concepts as simple as possible using the sensor fusion technology. This way, the technical security can be ensured for employees, machinery, equipment and processes as ubiquitous protection principle. The existing security concepts and techniques of the various protection areas using current sensor and communication technology networks can play a vital role so that not only the worker but also the machine or system must be protected.

\section{Classification of Robots in Food industry}

It is expected that the modern developments in lightweight industrial robots, will be equally applicable to the food industry seeking automation in all domains of production and packaging. These robots have advantage of being small as well as light in weight, convenient to use, sensitive to small scale commands and above all flexible in operation. These characterisitcs make them a suitable candidate for jobs that have not yet automated. Thanks to their integrated torque sensors and lower weight that provide additional degrees of freedom to cover all directions in the prescribed work envelop. These 'ready-to-deploy' robots are able to work in clean and hygienic but unstructured environments, to carry out tasks necessary for food processing.

Robots in food industry are mainly classified as per their usage in various tasks. However, it is also important to first understand the classification due to their mechanical arrangement or kinematics to map the correct application afterwards. 


\subsection{Classification w.r.t Kinematics}

Following classes are important to be presented in connection with industrial usage specially in the food sector.

\subsubsection{Portal robots}

These robots are mounted robotic systems that uses three linear axes to span a cubic handling area. The moving axes (actual robotic kinematics) are located above the mounting.

\subsubsection{Articulated robots}

These robots are industrial robots whose multiple interacting jointed arms can be fitted with grippers. Articulated robots offer a high degree of flexibility as, these arms can move through three dimensions,. Mostly, they can offer up to six degrees of freedom motion, which enables almost all types of movement. However, they have the constraint of restricted range and load capacity which makes them suitable for light weight industrial applications.

\subsubsection{SCARAs-Selective Compliance Assembly Robot Arms}

These articulated robots are equipped with a single arm capable of horizontal motion only. They work similar to human arms and therefore usually known as 'horizontal articulated arm robots'. SCARAs work in series by connecting to one another.

\subsubsection{Delta robots}

These spider-like robots are a distinctive arrangement of parallel robot which is classically based on 3 to 4 articulated axes with actuators which are stationary. The prime advantage of such robots is that they have only a small inertia as their actuators are located in the base. The main advantage of such robots is that they allow high speeds and acceleration.

\subsection{Classification w.r.t Application in Food industry}

The robots in food industry are also classified as per there application whether they are used for pick and place like food handling, packing and labelling, palletizing and for food serving applications. All the four categories are discussed in detail in this section.

\subsubsection{Pick and place}

The major trend to deploy robots in transforming food industry traditional processes is currently happening in the food handling category [62]. This category consists of the robots used for pick and place of food items and for food preparation. As per hygienic standards, it is required that the parts of the robot that comes into contact with food should be rust proof, washable and resistant against extreme temperatures, high humidity, soiling and mechanical stress. Also, the parts used for cutting should have smooth transitions with rounded corners and joint free design so as to avoid cleaning transitions and associated joints. 


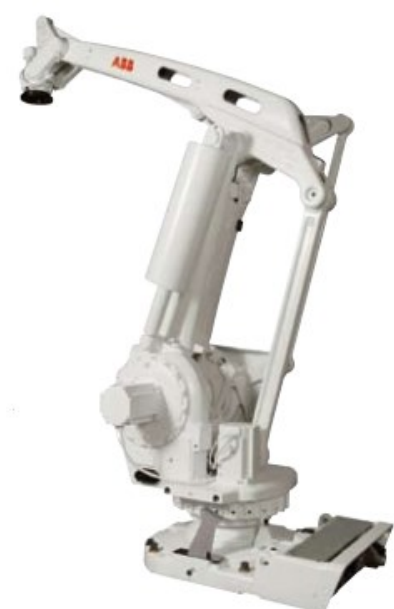

(a)

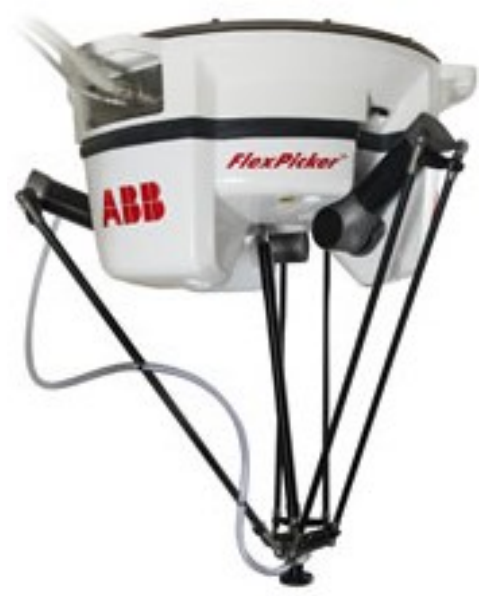

(b)

Figure 11. Food robots from ABB [28] (a) ABB's IRB-660 blending speed, reach and payload for the palletizing applications (serial configuration) (b) ABB's IRB-360 parallel configuration

Figure 11 shows ABB's pick and place expert robots mainly used in food handling applications. IRB-660 is a serial robot used for high demanding payload transfer. The other one is IRB-360 FlexPicker which is based on PKM mechanism [63]. It's main usage is in high-capacity collating, picking and placing of products and in other related tasks. Based on the Delta robot's outstanding motion performance, short cycle times, high capacity and accuracy can be achieved. It's other variant, the RacerPack can handle payloads of up to 300 grams at a rate of 450 items per minute. The system's customized collating grippers can pick up a wide variety of parts.

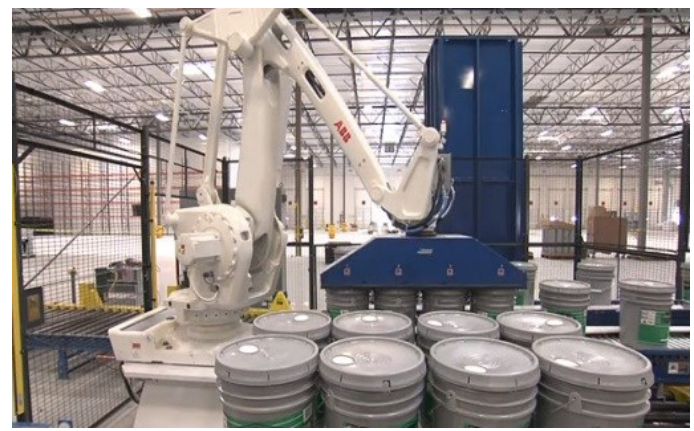

(a)

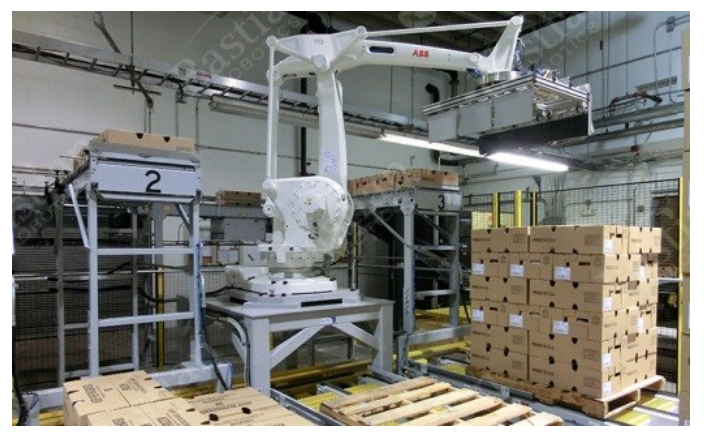

(b)

Figure 12. IRB 660 for palletizing applications [28] (a) Paint Boxes (b) Cartons

\subsubsection{Palletizing robots}

The second category refers to the packing and palletizing application in the food industry. These robots are used in palletizing of cookies, beverages, pasta, sweets and other food items which are stacked using these robots (See Fig. 12). For example, a developed solution allows production of 200 bags of $20 \mathrm{Kg}$ each per hour, and stacking them in order to minimize the freight costs. The companies which have employed such robotic systems for palletizing have entirely removed even wooden pallets from the process and therefore are taking advantage of the full capacity of shipping containers. Elimination of damage to bags is another benefit associated with this robotic application. The pallet management is also handled within the robot cells by specialized software and the designed tooling. This arrangement also determines 
the stack height of individual pallets and the orientation of the bins and cartons in the pallet using vision sensors, thereby, handling both bins and pallets.

\subsubsection{Packaging and Labelling robots}

These robots are specialized in packaging and labelling of the food items. FANUC LR Mate series robots are famous for labelling and packaging applications.Wrap labellers feeds blister packs while the label is wrapped around the part.

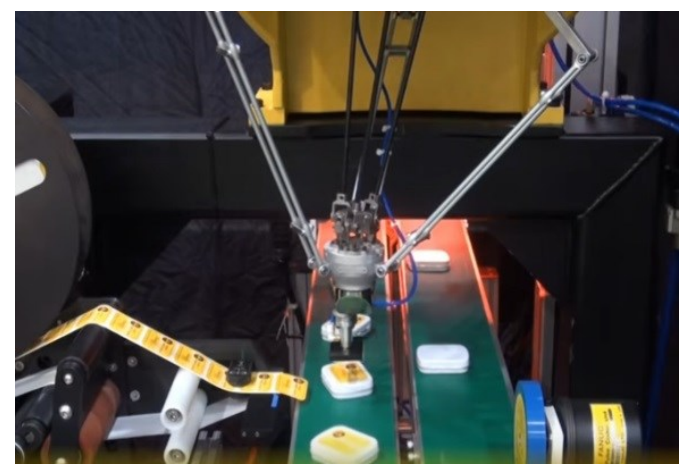

(a)

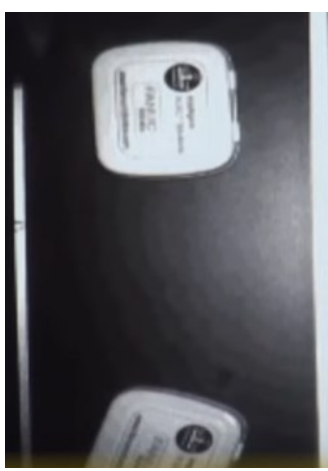

(b)

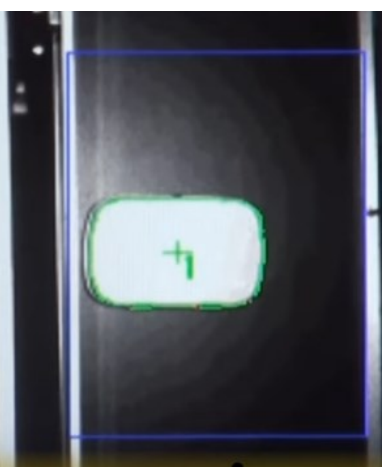

Figure 13. Labelling robots (a) FANUC M-1iA parallel link labelling robot (b) Camera monitoring and tracking for missing labels on food items which are separated and labelled afterwards [64]

Figure 13 shows a FANUC parallel link robot working in the area of food labelling. It is washable as it is designed for food processing and handling and the gripper directly touches the food. These robots for food preparation are available with simulation software like e.g. Delta robot (Flexpicker) is shipped with PickMasterTM software to facilitate the users of IRB 360. The use of these software tools simplifies vision configuration and offers the necessary features needed for efficient high speed picking tasks.

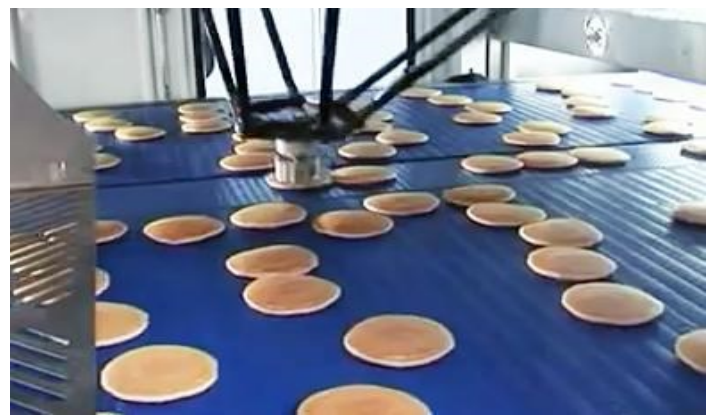

(a)

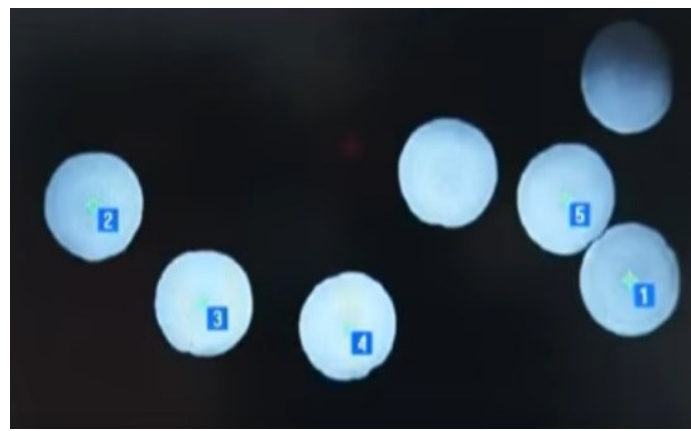

(b)

Figure 14. Inspection robots (a) ABB pan cake picker robot (b) High speed Ethernet cameras based inspection for stacking and positioning on the conveyer [28]

\subsubsection{Inspection and Testing}

It is customary to use purpose build robots for product inspection and testing. In a usual setting, the inspection and testing comes after the labelling robots finish up their work and the item is ready for packaging. Inspection is usually done with multiple cameras to verify the desired quality of finished product e.g. inspection of label on part. Failed parts get rejected and sent to the recheck bin whereas, the finished parts are sent over the conveyer belt for final transportation to the market. 
Checking and testing also includes the presence of item within the package using camera to ensure quality control.

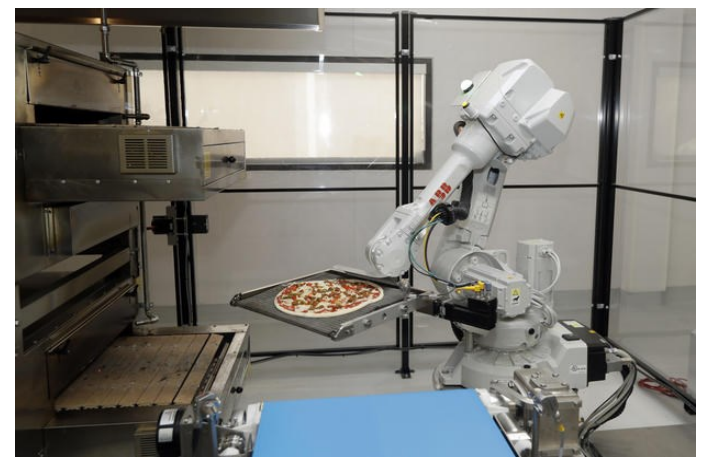

(a)

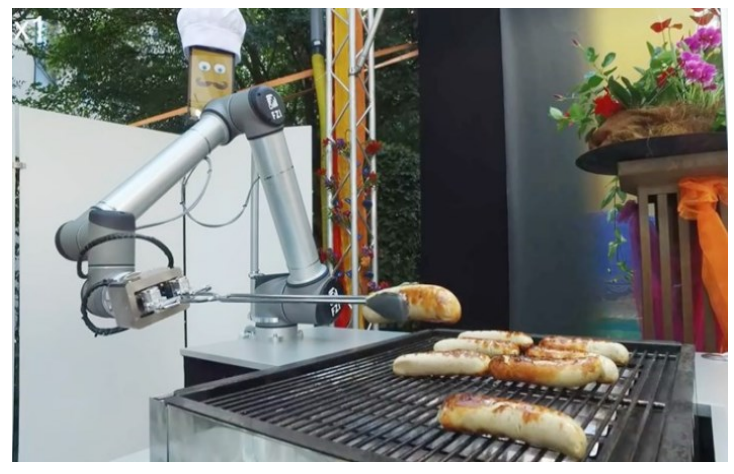

(b)

Figure 15. Robots in Kitchen: (a) Pizza-robot places a pizza into an oven at Zume Pizza in California, USA [65] (b) Little feller Chef robot [66]

Figure 14 shows the ABB pan picker robot connected with high speed cameras for automated visual servoing and image based stacking of cakes. Recently, low cost but high performance computing platforms are used with multiple video cameras to inspect quality of various food items in real time using deep learning algorithms [67, 68].

\subsubsection{Cooking Robots}

These robots are directly used to cook food. Chef robots are suitable in harsh and rugged environments e.g. in front of a Pizza oven at $800{ }^{\circ} \mathrm{C}$ temperature as shown in Figure 15a. They are also fascinating to look at when used to bake breads in front of guests as shown in Figure 15b. The vision based actuation control is not only provides a clean and tidy handling but also protects human operator from burning their hands in case of accidentally touching hot plates. Many fast food chains e.g. PizzaHut and McDonald's are planning to offer fully robotized food manufacturing while few humans will only be taking care of the machines busy in food preparation only to confirm the food quality and timely delivery [69].

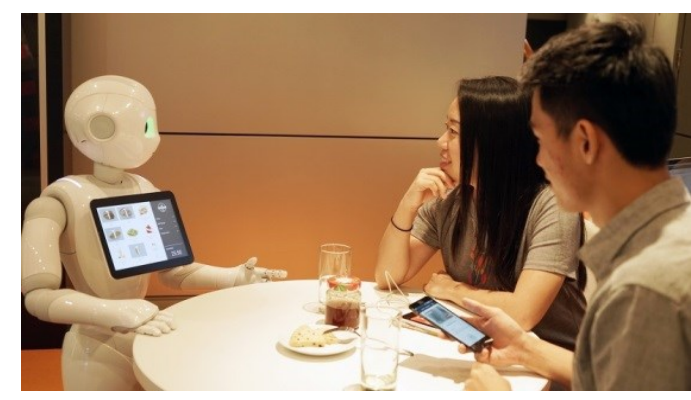

(a)

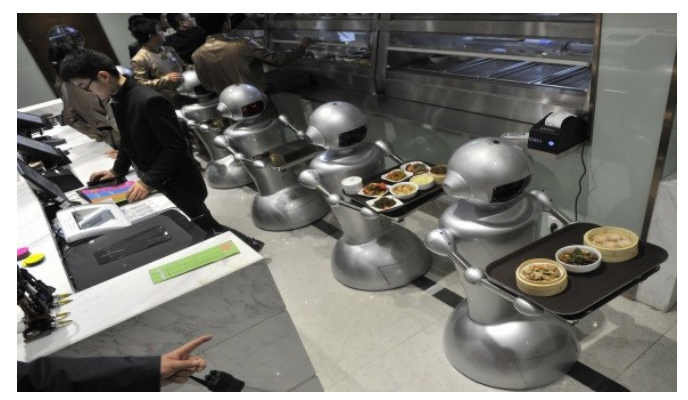

(b)

Figure 16. Robots in restaurants (a) Pizza Hut pepper robot [70] (b) Resturant Robots in China [71]

\subsubsection{Serving robots}

Recently, robots are used in resturants for guest reception and food distribution among customers [72]. Some prototypes are also in use for demonstration of this interesting technology [73] which is attributed as the human life-style change as well as a recreational activity. Thus, human system integration concepts are needed to be addressed [74]. Sushi resturants in Japan have started implementing the automated 
food lines to the customers which have become very popular by now. The flourishing idea of robot servers/waiters have emerged but still needs a commercial success in order to proceed further.

Figure 16a shows one such idea in which the wheeled footed serving robot presenting the food to the consumers. The idea needs to be flourished as it is a similar human-robot hybrid environment. The safety and protection issues need to be addressed as they have been realized in an industrial context. Chinese restuarants are being automatized using robots as shown in Figure 16b. Table 1 identifies the most popular robotic manipulators used in food industry with their specifications and handling capacity.

Table 1. Comparison of various robots in food industry and their specifications

\begin{tabular}{|c|c|c|c|c|c|c|c|c|}
\hline Purpose & Manipulator & DOF & $\begin{array}{c}\text { Workspace } \\
\text { Diameter } \\
{[\mathrm{mm}]}\end{array}$ & $\begin{array}{c}\text { Nominal } \\
\text { Payload } \\
{[\mathrm{kg}]} \\
\end{array}$ & $\begin{array}{c}\text { Repeatability } \\
\text { in translation } \\
{[\mathrm{mm}]} \\
\end{array}$ & $\begin{array}{l}\text { Performance } \\
\text { [cycles/min] }\end{array}$ & $\begin{array}{l}\text { Make/ } \\
\text { Origin }\end{array}$ & Ref \\
\hline \multirow{2}{*}{$\begin{array}{c}\text { Food } \\
\text { Packaging }\end{array}$} & HD-RL3/4-1100 & 3 & 1100 & 1 & $\leq \pm 0.1$ & 130 & $\begin{array}{l}\text { MAJAtronic, } \\
\text { Germany }\end{array}$ & {$[75]$} \\
\hline & $\begin{array}{c}\text { KR 16, } \\
\text { KR 30/60 }\end{array}$ & 6 & 3102 & 35 & $\begin{array}{c} \pm 0.05 \text { to } \\
\pm 0.08\end{array}$ & $>100$ & $\begin{array}{l}\text { KUKA, } \\
\text { Germany }\end{array}$ & {$[76]$} \\
\hline \multirow{3}{*}{$\begin{array}{l}\text { Picking } \\
\text { and } \\
\text { Placing }\end{array}$} & $\mathrm{M}-430 \mathrm{iA} / 2 \mathrm{~F}$ & 5 & 1130 & $1-2$ & \pm 0.5 & $120-100$ & FANUC, USA & {$[77]$} \\
\hline & KR AGILUS & 6 & 1101 & $6-10$ & \pm 0.03 & $70-80$ & $\begin{array}{l}\text { KUKA, } \\
\text { Germany }\end{array}$ & {$[76]$} \\
\hline & TS60 SCARA & 4 & 600 & 2 & \pm 0.01 & 100 & $\begin{array}{c}\text { Stäubli, } \\
\text { Switzerland }\end{array}$ & [78] \\
\hline \multirow{2}{*}{ Palletizing } & KR QUANTEC & 5 & 3195 & $120-240$ & \pm 0.06 & $80-100$ & $\begin{array}{l}\text { KUKA, } \\
\text { Germany }\end{array}$ & {$[76]$} \\
\hline & IRB 660 & 4 & 3150 & $180 / 250$ & \pm 0.5 & 80 & $\begin{array}{c}\mathrm{ABB}, \\
\text { Switzerland }\end{array}$ & [63] \\
\hline \multirow[t]{3}{*}{$\begin{array}{l}\text { Inspection } \\
\text { and testing }\end{array}$} & $\begin{array}{l}\text { FANUC M-1iA } \\
\text { parallel link } \\
\text { labelling robot }\end{array}$ & $3 / 4 / 6$ & $420(\max )$ & 1 (max) & \pm 0.02 & 40 & $\begin{array}{c}\text { FANUC, } \\
\text { Canada }\end{array}$ & [64] \\
\hline & $\begin{array}{c}\text { IRB } 360 \\
\text { FlexPicker robot }\end{array}$ & 4 & $1600(\max )$ & $1-8$ & \pm 0.1 & variable & ABB Robotics & [79] \\
\hline & IRB 4600s & $6+3$ & $4600(\max )$ & $20-60$ & $\pm 0.05-0.06$ & variable & ABB Robotics & {$[80]$} \\
\hline \multirow[t]{3}{*}{$\begin{array}{l}\text { Serving in } \\
\text { restaurants }\end{array}$} & $\begin{array}{c}\text { Pizza Hut pepper } \\
\text { robot }\end{array}$ & 17 & $\begin{array}{c}12 \text { hours } \\
\text { operation } \\
\text { with motion } \\
\text { speed up to } 2 \\
\mathrm{~km} / \mathrm{h}\end{array}$ & - & - & - & $\begin{array}{l}\text { SoftBank Corp/ } \\
\text { Aldebaran } \\
\text { Robotics }\end{array}$ & [81] \\
\hline & Connie & 14 & $1-1.5$ hours & - & - & - & Hilton/IBM & [82] \\
\hline & $\mathrm{Nao}$ & 14 & $1-1.5$ hours & - & - & - & $\begin{array}{c}\text { SoftBank Corp/ } \\
\text { Aldebaran } \\
\text { Robotics }\end{array}$ & [83] \\
\hline
\end{tabular}

\section{Challenges and Opportunities}

As discussed previously, unmatchable performance can be ensured by robots for repetitive and non-repetitive tasks executed in food processing industry. However, some challenges are still present with this easiness [84].

\subsection{Challenges in Food sector Robotics}

Some challenges for introducing robots in food processing are as follows: 


\subsubsection{Augmented intelligence}

It is important to note that in today's world of food and beverage industry, instead of 'intelligent work' robots are mainly used for 'heavy work', i.e. for packing, palletising and repacking tasks. Normally, they are used to work on packaged foods whose handling task is relatively easy and can be carried out with a standard operating procedure (SOP) by incorporating general purpose robots. However, for direct use of robots in the actual food production, where they are supposed to come into direct contact with food, a single standard must be agreed upon by the robot manufacturers. Most of the food products composed of natural ingredients, have specific rheological properties which makes it very challenging to be operated by robots due to their high sensitivity to mechanical interference.

\subsubsection{Food Safety and Hygiene}

Food robots are highly sophisticated systems satisfying stringent hygienic requirements of food industry that meet the relevant cleaning and disinfection protocols. As both the food and machinery can be the source of corrosive properties, the environmental conditions in food production are often regarded as complex; while the ambient temperature can range from extremely hot to well below freezing.

\subsubsection{Controlled environments using Food robots}

The stringent requirements on food handling while simultaneously maintaining hygienic standards demand controlled environments in the food industry. The food robots are considered easier to operate in controlled environments as compared to their human counterparts. The use of robots in the food and beverage industry makes them a helping hand to speed up the production process in a sensible and desirable fashion.

\subsubsection{Cost effective production cycle}

The wide range of production demand with extensive product ranges in food industry requires flexibility at various levels to accommodate highly variable space and performance specifications. The major requirement is to address the challenge of maximising efficiency and reducing costs. It is very hard for workers to spend 8 hours a day performing a repetitive action over and over again at a temperature of $8{ }^{\circ} \mathrm{C}$. Moreover, it is not likely to spend the best part of the day working in a freezer while simultaneously ensuring the stringent hygienic requirements of the food industry to avoid the microbial contamination due to human skin. Also, a continuous production demand of $24 \mathrm{hrs}$ work load is not cost-effective keeping in view the transportation of the workers, their salary expense, leaves and other facilities, retirement benefits etc. which could cost much higher to the food industry.

\subsection{Possible solutions and opportunities}

It is our objective to present how such critical issues could be dealt with robotics technology with high precision and accuracy. Some details are listed as under:

\subsubsection{Maintaining Hygiene - food grade robots}

A major challenge with respect to using robots in food production arises if they are required to work directly with food. Then, the hygienic requirements must be satisfied by cleaning them properly and with the standard procedure of disinfecting them. A variety of solutions are being implemented to maintain the hygienic design of food robots. Specifically, 'wash-down robots' are equipped with IP65 compliant 
hygiene cover which can be washed/changed easily [85]. Some producers choose protective coatings in their designs e.g. epoxide, or a full stainless steel based design, which does not chemically react with cleaning agents/acids/alkalis etc. The lubricants used with these robots are also food-grade (certified NSF H1). Despite all this progress, there are indeed more advanced developments that are possible to achieve in food-grade robots.

\subsubsection{Cyber Physical System (CPS) in food industry}

The robots for food preparation, handling and serving need to work in the same environment with the assisted sensing to make their learning environment as foreseen by the fourth industrial revolution (industry 4.0) [86]. From raw material to final product, this transformation provides a modular approach for optimized performance as shown in Fig. 17. A complete CPS consists of simulation designs to effectively generate scenes and solutions to the problem of sensing data fusion and communication through a network and physical robots [87]. Building a CPS is much bigger problem than merely developing a control law for a single robot or designing its control interface. It is a comprehensive issue covering all dimensions of the control, sensing, machines, communication, system engineering and integration [88].

A unique opportunity lies in the effective development of such ideas in food handling and serving categories [89]. The new technology areas included in robotics research is development of new Human Machine Interfaces (HMI) to facilitate user's interaction with the robots [90]. HMI needs to be user friendly, fast and reliable to handle big data while ensuring robust and fault tolerant characteristics.

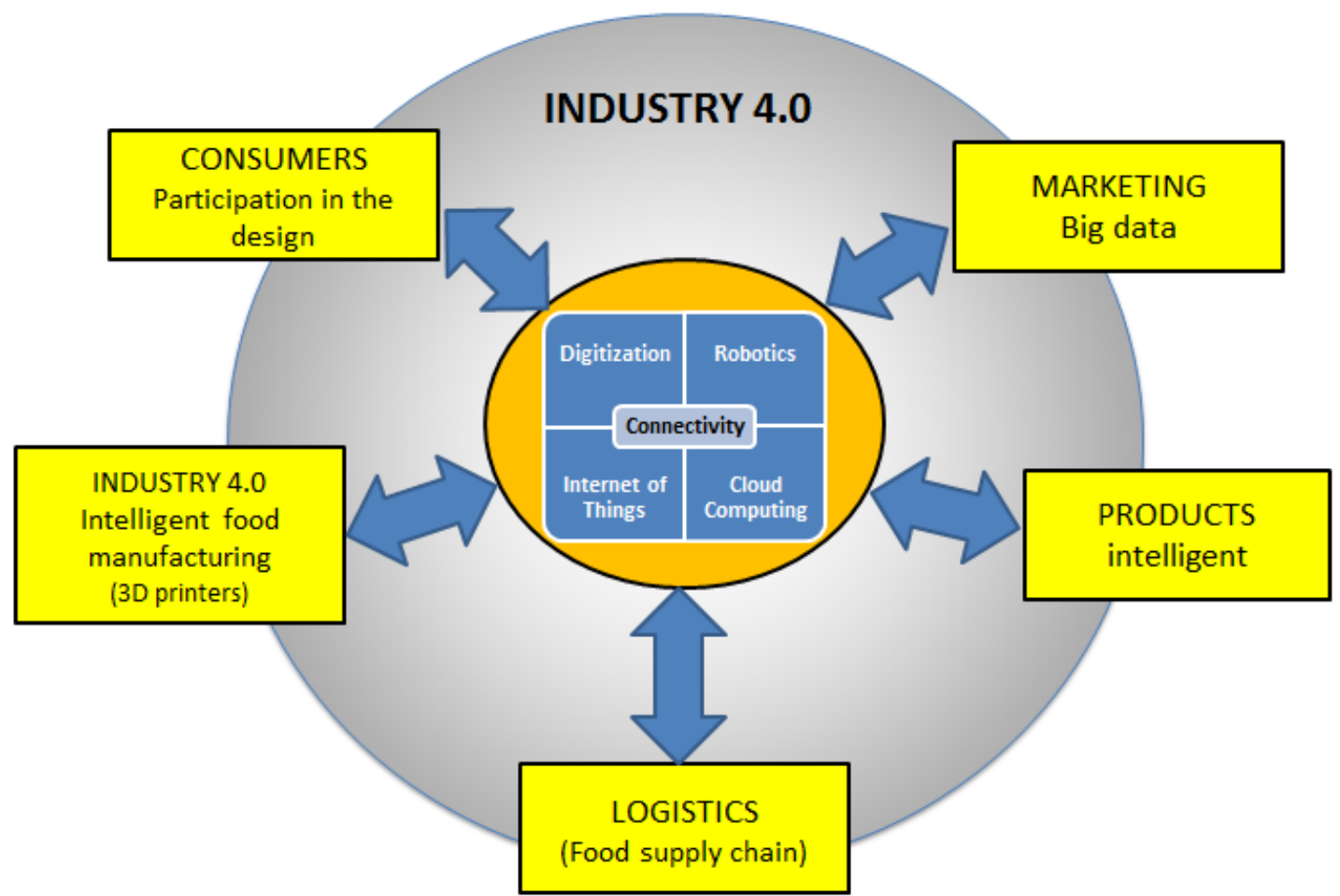

Figure 17. Intelligent food processing in the context of Industry 4.0

The basic independent functinlaities of the robotics CPS in intelligent food manufacturing system is shown in Fig. 18. This in actual constitutes a Cyber Physical Production system (CPPS) for food manufacturing with intelligent modules and subsystems, highly automated to develop self learning capabilities. The cyber layer which 
interacts with the other two layers has infact the largest attack surface which is a must to safeguard against sophisticated cyber-attacks [91]. If the cyber layer is compromised, the cyber-attack may directly effect the control layer and the precious physical layer comprised of robots, physical food processing plant modules, actuators and sensors. The basic interactions in the CPS network are supported by adaptor technologies that can be used to make the interface smooth or may be used for system redundant resources, in case the system's cyber or control layer is compromised under a cyber-attack [92]. Adaptors may also have additional secure nodes to prevent the permanent damage of the physical layer. This model best suits the intelligent food manufacturing CPPS [93]. The biggest challenge is to safeguard such a system due to high connectivity level from ever increasing (target's knowledge oriented) cyber attacks.

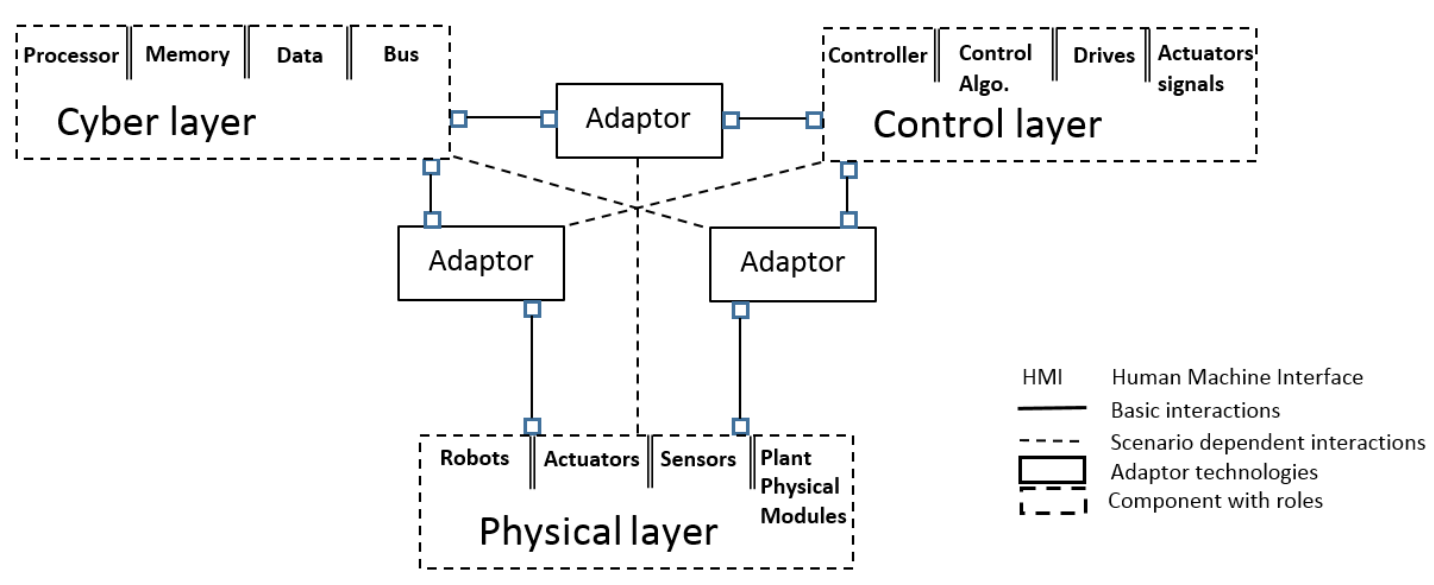

Figure 18. CPS model for food manufacturing: Cyber, control and physical layers

There is another model for the food serving industry which has different attributes than the food manufacturing CPS. This is an opportunity in the food service industry to develop an integrated and highly automated system with self decision making devices and sub-systems connected together. This is a direct implementation of an Anthropocentric CPS (ACPS) in which the human act as a necessary component of the integrated CPS as shown in Fig. 19.

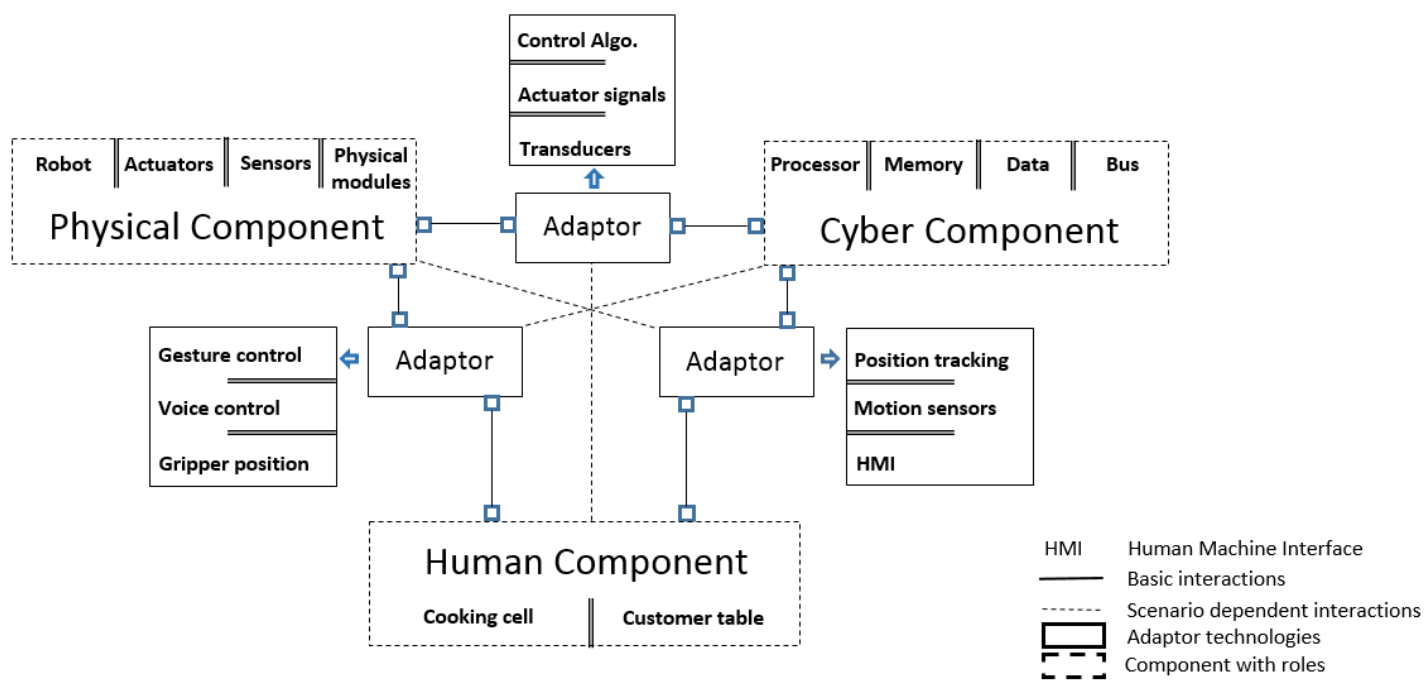

Figure 19. ACPS model for food serving industry: Cyber component, physical component and human component at two process ends 
It is rather an extension of ACPS in a sense that the serving robot CPS has human interaction in two ways. First, the human centric cooking process from where the serving robot is loaded with the food. Here, the cooking cell needs to be designed in a way that a human robot collaboration can takes place. For the human centric activities in a cooking cell, if the serving robot is allowed to work or support human in cooking process, the collaboration process, cooking cell design, technology selection and the nature of tasks by the robot must be defined in the ACPS. The second human interaction takes place at the serving end to the customer where the regular activities of the robot can be to cheer the customers, serve the food according to the individual order on the table and the billing process. The customer table design again requires a safe human robot collaboration process and selection of appropriate technology modules. The ACPS structure for the complete serving process is shown below.

\subsubsection{Dependable Software}

Software solutions are an integral part of the robotic implementation of a product line. For food industry applications, the software must be robust due to rapidly changing product type [94]. The solution needs to be open-source so that others can form an application layer of functional modules on top of the basic platform and could guarantee an autonomous behaviour. It must be robust and fault tolerant (self-healing) in failure scenarios. The software architecture is required to be flexible, reconfigurable and adaptive and should not be preferably specific to a particular robot or a task. One such example is of RobotStudio for IRB 660 by ABB. In this application tool, users can perform installations in the system via a computer [52]. The system can also be used while the robot is operating and allows for remote maintenance. The software can simulate all the robot movements in order to ensure the reachability for the pick positions. A similar example is of PickMaster ${ }^{\mathrm{TM}}$ software for IRB 360 system with user and integrator support provided by the same company. Setting up an application using the software becomes easy with the help of vision configuration with efficient tools needed for high speed picking. Another software solution PowerPac reduces the risks of a picking line by testing and minimizing the variations in the product inflow [95]. The software allows for the improvement of existing lines by recording current product flow with cameras and then feeding the data to get more robust solution.

Using such Graphical User Interface (GUI) based software solutions, the food production line can be designed at the very initial phase since the interface permits the user to see and answer broader questions such as where to position the robots for maximum output. In the virtual world, the user can simply move, add or remove robots and move conveyors around until all positions are reachable, optimized and verified. Programs can then be tuned for speed and process efficiency with cycle times verified and optimized before actual system installation. Another benefit of a GUI is that the user does not have to write codes for all the pre-installation activity [96]. Other feature for such software solutions is the ability to integrate and support various powerful algorithms and new modules which will evolve in future.

\subsubsection{Sensor interfacing}

Sensing requirements are increasing for the robotic applications used in food industry. The demand is coming from various aspects like CPS, DOF, application, human-robot interaction and safety concepts [97]. All of these technology areas have their specific sensing requirements. For example, in designing a CPS for a number of 
robots, vision sensor (high speed camera) is an integral part. Integrated vision is a powerful smart camera system used for visual servoing and other vision-guided robotics applications [98]. CPS needs vision based mapping system for which the robot can assess the position of the human worker. For that, even the human worker also needs some wearable sensors like google glass. This type of CPS can ensure safe operations in a hybrid environment. Moreover, using 2D-vision based guidance; manufacturers are able to accurately track products and improve supply chain management, product quality, diagnose faults, optimize production and significantly expand the use of robotic automation. Vision-guided robotics can save time, money and resources.

The other challenging area is to meet the power requirements of industrial robots as the power requirements increases for large payload capacity robots. Analysis of energy consumption of a manipulator involves in-depth study of its kinematics and dynamics in addition to requirements of the targeted application, placement of objects in robot's workspace and efficiency of path planning algorithm [99]. A manipulator's kinematics and dynamics dictate that energy consumption is affected by inertia tensor of each link and the required torque on each joint [100]. Designing of optimal and low cost power solution is always a requirement for actuation of such systems [101]. Such actuators normally use servo and brushless DC magnetic motors for precision applications. Studies reported in address analysis and reduction in energy consumption of industrial robots [102].

\section{Viewpoints on Industry 4.0 implementation in food manufacturing system}

The current focus in food sector emphasizes on food manufacturing as well as the food serving applications connected through a common cyber layer which has the largest attck surface from external sources and must be treated with security strategies that would be different from the security shield for a common IT network [103, 104]. Industry 4.0 vision is different from the current architecture in that the smart factory ensures safety and analyzes data as a requirement and thus avoids down time due to the lack of maintenance or failure. Moreover in the framework of industry 4.0, cognitive processing using wireless autonomous, reliable and resilient production operation architecture based CPS. Cognitive processing for safety requires scene recognition, learning by demonstration and human interfacing. System control of multiple collaborative robots with machine to machine communication through networks becomes a complicated task. Additionally, the HD camera based vision systems for robot tracking and local mapping are the software based solutions specifically developed according to the demand of such applications [105].

The prime advantage of next generation food CPS is the autonomy achieved in the plant installations, for instance, it automatically keep a fermenting process within a certain temperature window throughout operation. For the simplification and speeding up in food processing of composite products, such systems are increasingly being integrated into plant and machinery and then take over regulating tasks selfreliantly [106]. These embedded systems become interactive and communicate with each other to implement machine-to-machine communication, or M2M.

\section{Conclusion}

This paper presents a comprehensive overview of the robotic's potential in food processing industry is presented. In today's competitive business environment, there is increasing pressure to produce "more with less" and simultaneously meet the everchanging demands of the customers which is only possible with the recent progress in 
advanced flexible manipulators. It is revealed that the robotics have significantly augmented the yield as compared to the manual systems. The paper has described the kinematic and dynamic modelling issues of such robots. Classifications of robot systems are presented based on three categories; Food handling and processing, Palletizing and packing and Food serving. It is emphasized that the food serving sector has the leading prospects of research and technology development. Many opportunities are present in embedded control, speech processing, CPS design, sensor fusion, robot operating system (ROS) design, vision systems, fault tolerant control etc. The new concepts and trends are evolving based on the supporting technologies that were not available previously. A number of stake-holders, ranging from investors in shared robot technology to FDA approvals of robot use, appear to boost both nearand long-term growth prospects for the robotics industry in food and allied technologies. The urgent requirement is to simultaneous incorporate various technologies e.g. CPS, IoT, machine learning, cloud systems, cyber security and autonomous robots in a collaborative environment to join hands for emerging solutions as proposed by industry 4.0.

\section{References}

[1] M. P. Groover, M. Weiss, R. N. Nagel, and N. G. Odrey, Industrial Robotics: Technology, Programming, and Applications: McGraw-Hill New York, 1986.

[2] J. Iqbal, S. A. Ajwad, S. Z. Abbas, A. A. Khan, and R. U. Islam, "Automating industrial tasks through mechatronic systems - A review of robotics in industrial perspective," Tehnički vjesnik- Technical Gazette, vol. 23, 2016.

[3] W. Alam, A. Mehmood, K. Ali, U. Javaid, S. Alharbi, and J. Iqbal, "Nonlinear control of a flexible joint robotic manipulator with experimental validation," Strojniški vestnik - Journal of Mechanical Engineering, vol. 64, pp. 47-55, 2018.

[4] P. Chua, T. Ilschner, and D. Caldwell, "Robotic manipulation of food products-a review," Industrial Robot: An International Journal, vol. 30, pp. 345-354, 2003.

[5] J. N. Pires, Industrial robots programming: Building applications for the factories of the future: Springer Science \& Business Media, 2007.

[6] A. Mechraoui, Z. H. Khan, J.-M. Thiriet, and S. Gentil, "Co-design for wireless networked control of an intelligent mobile robot," in International Conference on Informatics in Control, Automation and Robotics (ICINCO), 2009, p. 7.

[7] IFR. World Robotics [Online]. Available: https://ifr.org/downloads/press/Presentation_PC_27_Sept_2017.pdf

[8] R. J. M. Masey, J. O. Gray, T. J. Dodd, and D. G. Caldwell, "Guidelines for the design of lowcost robots for the food industry," Industrial Robot: An International Journal, vol. 37, pp. 509-517, 2010.

[9] A. Kumari and V. Chawla, "Trends in automatic quality inspection and grading of food and agricultural products by machine vision - A review," International Journal of Advanced Research in Computer Science, vol. 6, 2015.

[10] J. Iqbal, Z. H. Khan, and A. Khalid, "Prospects of robotics in food industry," Food Science and Technology (Campinas), vol. 37, pp. 159-165, 2017.

[11] M. Wilson, "Developments in robot applications for food manufacturing," Industrial Robot: An International Journal, vol. 37, pp. 498-502, 2010.

[12] J. O. Gray, S. T. Davis, and D. G. Caldwell, "Robotics in the food industry: an introduction," Robot Automation food Ind Current and Future Technology, pp. 21-35, 2013.

[13] R. Tillett, "Image analysis for agricultural processes: a review of potential opportunities," Journal of agricultural Engineering research, vol. 50, pp. 247-258, 1991.

[14] S. Choi, G. Zhang, T. Fuhlbrigge, T. Watson, and R. Tallian, "Applications and requirements of industrial robots in meat processing," in Automation Science and Engineering (CASE), 2013 IEEE International Conference on, 2013, pp. 1107-1112.

[15] P. J. Wallin, "Robotics in the food industry: An update," Trends in food science \& technology, vol. 8, pp. 193-198, 1997. 
[16] F. D. (2014, 9 April). Farming Drones-UAVs in the Agriculture Industry. Available: www.farmingdrones.com

[17] M. E. Abid, "Drones, UAVs, and RPAs," WORCESTER POLYTECHNIC INSTITUTE, 2014.

[18] H. Saari, I. Pellikka, L. Pesonen, S. Tuominen, J. Heikkilä, C. Holmlund, et al., "Unmanned Aerial Vehicle (UAV) operated spectral camera system for forest and agriculture applications," in Proc. SPIE Remote Sensing for Agriculture, Ecosystems, and Hydrology XIII, Czech Republic, 2011.

[19] G. J. Grenzdörffer, B. Teichertc, and A. Engelb, "The photogrammetric potential of low-cost UAVs in forestry and agriculture," Int. Arch. Photogramm. Remote Sens. Spat. Inf. Sci, vol. 37, pp. 1207-1213, 2008.

[20] J. P. Merlet, Parallel Robots: Kluwer Academic Publishers, 2000.

[21] I. Bonev, "Delta parallel robot - The story of success," 2001.

[22] N. P. Mahalik and A. N. Nambiar, "Trends in food packaging and manufacturing systems and technology," Trends in food science \& technology, vol. 21, pp. 117-128, 2010.

[23] G. Purnell and D. Caldwell, "Robotics and automation in meat processing," Robotics and automation in the food industry: current and future technologies, pp. 304-328, 2013.

[24] Y. Kusuda, "The use of robots in the Japanese food industry," Industrial Robot: An International Journal, vol. 37, pp. 503-508, 2010.

[25] L. W. Tsai, Robot Analysis: The Mechanics of Serial and Parallel Manipulators. New York: John Wiley \& Sons, 1999.

[26] S. A. Ajwad, J. Iqbal, R. U. Islam, A. Alsheikhy, A. Almeshal, and A. Mehmood, "Optimal and robust control of multi DOF robotic manipulator: Design and hardware realization," Cybernetics and Systems, vol. 49, pp. 77-93, 2008.

[27] S. Manzoor, R. U. Islam, A. Khalid, A. Samad, and J. Iqbal, "An open-source multi-DOF articulated robotic educational platform for autonomous object manipulation," Robotics and Computer-Integrated Manufacturing, vol. 30, pp. 351-362, 2014.

[28] ABB. (2015, 2nd February). Power and Productivity for a better world. Available: www.abb.com

[29] C. R., " DELTA, a fast robot with parallel geometry," in 18th Int. Symp. on Industrial Robot, 1988, pp. 91-100.

[30] C. Blanes, M. Mellado, and P. Beltran, "Novel Additive Manufacturing Pneumatic Actuators and Mechanisms for Food Handling Grippers," in Actuators, 2014, pp. 205-225.

[31] A. Khalid, S. Mekid, and A. Hussain, "Characteristic Analysis of bioinspired pod structure robotic configurations," Cognit. Comput, vol. 6, pp. 89-100, 2013.

[32] L. Y. J. and S. S. M., "A comparative study of inverse dynamics of manipulators with closed chain geometry," Robot. Syst, vol. 7, pp. 507-534, 1990.

[33] T. Brogårdh, "Robot control overview: An industrial perspective," Modeling, Identification and Control, vol. 30, pp. 167-180, 2009.

[34] F. Lin and R. D. Brandt, "An optimal control approach to robust control of robot manipulators," IEEE Transactions on Robotics and Automation, vol. 14, pp. 69-77, 1998.

[35] S. Khan, W. Naeem, R. Sutton, and S. Sharma, "Application of soft computing techniques to a LQG controller design," in Advanced Design and Manufacture to Gain a Competitive Edge, ed: Springer, 2008, pp. 137-146.

[36] T. Blevins, "PID advances in industrial control," in Preprints IFAC Conference on Advances in PID Control, Italy, 2012.

[37] S.A. Ajwad, U. Iqbal, and J. Iqbal, "Hardware realization and PID control of multi-degree of freedom articulated robotic arm," Mehran University Research Journal of Engineering and Technology, vol. 34, pp. 1-12, 2015.

[38] R. U. Islam, J. Iqbal, and Q. Khan, "Design and comparison of two control strategies for multi-DOF articulated robotic arm manipulator," Journal of Control Engineering and Applied Informatics, vol. 16, pp. 28-39, 2014.

[39] M. I. Ullah, S. A. Ajwad, M. Irfan, and J. Iqbal, "Non-linear control law for articulated serial manipulators: Simulation augmented with hardware implementation," Elektronika Ir Elektrotechnika 2016.

[40] S. A. Ajwad, M. I. Ullah, B. Khelifa, and J. Iqbal, "A comprehensive state-of-the-art on control of industrial articulated robots," Journal of the Balkan Tribological Association, vol. 20, pp. 499-521, 2014. 
[41] M. F. Khan, R. U. Islam, and J. Iqbal, "Control strategies for robotic manipulators," in IEEE nternational Conference on Robotics and Artificial Intelligence (ICRAI), Pakistan, 2012, pp. 26-33.

[42] S. A. Ajwad, J. Iqbal, M. I. Ullah, and A. Mehmood, "A systematic review of current and emergent manipulator control approaches," Frontiers of Mechanical Engineering, Springer, 2015 - In Press.

[43] J. Iqbal, M. Ullah, S. G. Khan, B. Khelifa, and S. Ćuković, "Nonlinear control systems-A brief overview of historical and recent advances," Nonlinear Engineering - Modeling and Application, vol. 6, pp. 301-312, 2017.

[44] W. He and Y. Dong, "Adaptive fuzzy neural network control for a constrained robot using impedance learning," IEEE transactions on neural networks and learning systems, 2017.

[45] K. Dogan, E. Tatlicioglu, E. Zergeroglu, and K. Cetin, "Learning Control of Robot Manipulators in Task Space," Asian Journal of Control, 2018.

[46] G. Grigore, "Mobility of mechanisms: a critical review," Mech. Mach. Theory, vol. 40, pp. 1068-1097, 2005.

[47] Y.-M. Moon and S. Kota, "Generalized Kinematic Modelling of Reconfigurable Machine Tools," ASME J. Mech. Des, vol. 124, pp. 47-51, 2002.

[48] S. Gunasekaran, "Computer vision technology for food quality assurance," Trends in Food Science \& Technology, vol. 7, pp. 245-256, 1996.

[49] J. Holmes. (2014, 10th December). Developing a Washable Robot for Poultry Processing. Available: http://gtri.gatech.edu/casestudy/developing-washable-robot-poultry-processing

[50] JLS. (2016, June 2016). Talon ${ }^{\mathrm{TM}}$ Pick and Place Packaging Systems. Available: http://www.jlsautomation.com/automated-food-packaging/talon-packaging-systems.php

[51] Multipack. (2005). Cosmetic Cream Cup Filling Sealing Machine. Available: http://www.liquidfillingmachines.net/cosmetic_cream_cup_filling_sealing_machine.html

[52] C. Connolly, "Technology and applications of ABB RobotStudio," Industrial Robot: An International Journal, vol. 36, pp. 540-545, 2009.

[53] E. Ngai, F. Suk, and S. Lo, "Development of an RFID-based sushi management system: The case of a conveyor-belt sushi restaurant," International Journal of Production Economics, vol. 112, pp. 630-645, 2008.

[54] Y. Shimizu, "Conveyer-belt sushi control system capable of controlling amount of sushi," ed: Google Patents, 2005.

[55] DigPlanet. (2013, 2nd January). Conveyer Belt Sushi. Available: http://www.digplanet.com/wiki/Conveyor_belt_sushi

[56] F. Erzincanli and J. Sharp, "Meeting the need for robotic handling of food products," Food Control, vol. 8, pp. 185-190, 1997.

[57] Y. Hasegawa and N. Sugimoto, "Industrial safety and robots," in Proceedings of the 12th International Symposium on Industrial Robots, 1982, pp. 9-15.

[58] S. Oberer and R. D. Schraft, "Robot-dummy crash tests for robot safety assessment," in Robotics and Automation, 2007 IEEE International Conference on, 2007, pp. 2934-2939.

[59] F. Bender and G. Kahan, "Agriculture and the Food Industry," Encyclopedia of Operations Research and Management Science, pp. 16-19, 2013.

[60] Y. Li, M. H. Lee, M. Rodrigues, and J. J. Rowland, "A visually guided robot system for food handling applications," in Robotics and Automation, 1994. Proceedings., 1994 IEEE International Conference on, 1994, pp. 2591-2596.

[61] T. Brogårdh, "Present and future robot control development-An industrial perspective," Annual Reviews in Control, vol. 31, pp. 69-79, 2007.

[62] F. Erzincanli and J. Sharp, "A classification system for robotic food handling," Food Control, vol. 8, pp. 191-197, 1997.

[63] ABB, "ABB Robotics launches simple programming tool," Assembly Automation, vol. 27, 2007.

[64] T. Proietti, "FANUC Canada Demontrates M-1iA Parallel-Link Robot at Advanced Manufacturing, Canada," ed, 2015, pp. 1-3.

[65] C. News. (2016). Invasion of the pizza-making robots. Available: http://www.cbsnews.com/news/invasion-of-the-pizza-making-robots/

[66] Altish. (2016, November 23). Restaurant robots: service jobs are history Available: http://www.altish.com/retail/restaurant-robots-service-jobs-will-dissapear/

[67] H. A. Pierson and M. S. Gashler, "Deep learning in robotics: a review of recent research," Advanced Robotics, vol. 31, pp. 821-835, 2017. 
[68] L. Pan, S. Pouyanfar, H. Chen, J. Qin, and S.-C. Chen, "DeepFood: Automatic Multi-Class Classification of Food Ingredients Using Deep Learning," in 2017 IEEE 3rd International Conference on Collaboration and Internet Computing (CIC), 2017, pp. 181-189.

[69] M. Sedacca. (2016). Are Robots Really Destined to Take over Resturant Kitchens?

[70] D. Reisinger. (2016). Pizza Hut adding "Pepper Robots" to restaurants in Asia Available: http://in.pcmag.com/robotics-automation/103569/news/pizza-hut-adding-pepper-robots-torestaurants-in-asia

[71] C. Nguyen. (2016). Restaurants in China are replacing waiters with robots.

[72] C. Jennings, M. Katchmar, W. Hickle, Z. A. Michael, and C. Traynor, "Robotic beverage server," ed: Google Patents, 2005.

[73] M. Asif, Jan, S., Ur Rahman, M., \& Khan, Z. H., "Waiter Robot - Solution to Restaurant Automation," in 1st Student Multi Disciplinary Research Conference (MDSRC), Wah, 2015.

[74] H. R. Booher, Handbook of Human Systems Integration: Wiley, 2003.

[75] MAJAtronic, "Hygienic Design Delta Robot," 2015.

[76] KUKA, "Robots for the food processing industry," 2015.

[77] FANUC, "M-430iA/2F," ed, 2014.

[78] Staubli. (2015, 20th Feb). TS60 SCARA robot. Available: http://www.staubli.com/en/robotics/6-axis-scara-industrial-robot/low-payload-6-axis-scararobot/ts60/

[79] IPA, "Technical data for the IRB 360 industrial robot," in http://new.abb.com/products/robotics/industrial-robots/irb-360/irb-360-data, ABB, Ed., ed, 2016.

[80] A. A. Robotics, "IRB 4600 datasheet," in http://new.abb.com/products/robotics/industrialrobots/irb-4600, ABB, Ed., ed. Sweden, 2016.

[81] S. Corp. (2015) Pepper-the World's first personal robot that reads emotions. New Breeze. Available: 4 web 06 ROBOTS pepper.pdf

[82] N. Statt. (2016). Hilton and IBM built a Watson-powered concierge robot.

[83] AR, "NAO Humanoid Robot Platform," ed: Aldebaran Robotics, France, 2012.

[84] M. Mueller, B. Kuhlenkoetter, and R. Nassmacher, "Robots in Food Industry Challenges and Chances," ISR/Robotik 2014, 2014.

[85] J. Trienekens and P. Zuurbier, "Quality and safety standards in the food industry, developments and challenges," International Journal of Production Economics, vol. 113, pp. 107-122, 2008.

[86] C. Fuchs, "Industry 4.0: The Digital German Ideology," tripleC: Communication, Capitalism \& Critique. Open Access Journal for a Global Sustainable Information Society, vol. 16, pp. 280-289, 2018.

[87] Z. H. Khan, A. S. Ali, and Z. Riaz, Computational Intelligence for Decision Support in CyberPhysical Systems vol. 540: Springer, 2014.

[88] H. Smajic and N. Wessel, "Remote Control of Large Manufacturing Plants Using Core Elements of Industry 4.0," in Online Engineering \& Internet of Things, ed: Springer, 2018, pp. 546-551.

[89] P. Zheng, Z. Sang, R. Y. Zhong, Y. Liu, C. Liu, K. Mubarok, et al., "Smart manufacturing systems for Industry 4.0: Conceptual framework, scenarios, and future perspectives," Frontiers of Mechanical Engineering, pp. 1-14, 2018.

[90] S. G. Khan, G. Herrmann, A. Lenz, M. Al Grafi, T. Pipe, and C. Melhuish, "Compliance control and human-robot interaction: Part II- Experimental examples," International Journal of Humanoid Robotics, vol. 11, 2014.

[91] J. Ambrose, A. Ignjatovic, and S. Parameswaran, Power Analysis Side Channel Attacks: The Processor Design-level Context: VDM Publishing, 2010.

[92] A. Khalid, P. Kirisci, Z. Ghrairi, K.-D. Thoben, and J. Pannek, "A methodology to develop collaborative robotic cyber physical systems for production environments," Logistics Research, vol. 9, p. 23, 2016.

[93] A. Khalid, P. Kirisci, Z. Ghrairi, J. Pannek, and K.-D. Thoben, "Safety Requirements in Collaborative Human-Robot Cyber-Physical System," in Dynamics in Logistics, ed: Springer, 2017, pp. 41-51.

[94] R. Pack, D. M. Wilkes, and K. Kawamura, "A software architecture for integrated service robot development," in Systems, Man, and Cybernetics, 1997. Computational Cybernetics and Simulation., 1997 IEEE International Conference on, 1997, pp. 3774-3779. 
[95] S. Derby and C. Connolly, "ABB high-speed picking robots establish themselves in food packaging," Industrial Robot: An International Journal, vol. 34, pp. 281-284, 2007.

[96] Y. Sugiura, D. Sakamoto, A. Withana, M. Inami, and T. Igarashi, "Cooking with robots: designing a household system working in open environments," in Proceedings of the SIGCHI Conference on Human Factors in Computing Systems, 2010, pp. 2427-2430.

[97] N. Wang, N. Zhang, and M. Wang, "Wireless sensors in agriculture and food industryRecent development and future perspective," Computers and electronics in agriculture, vol. 50, pp. 1-14, 2006.

[98] P. Barreiro Elorza, E. C. Correa Hernando, F. J. Arranz Saiz, B. Diezma Iglesias, L. Ruiz García, M. Villarroel, et al., "Smart Sensing Applications in the Agriculture and Food Industry," 2011.

[99] B. Schmidt, A. Mohammed, and L. Wang, "Minimizing energy consumption for robot arm movement " in International Conference on Advanced Manufacturing Engineering and Technologies (NEWTECH), Sweden, 2013.

[100] M. Chemnitz, G. Schreck, and J. Kruger, "Analyzing energy consumption of industrial robots," in IEEE Conference on Emerging Technologies \& Factory Automation (ETFA), France, 2011, pp. 1-4.

[101] A. Mohammed, B. Schmidt, L. Wang, and L. Gao, "Minimizing energy consumption for robot arm movement," Procedia CIRP (The International Academy for Production Engineering), vol. 25, pp. 400-405, 2014.

[102] M. Pellicciari, G. Berselli, F. Leali, and A. Vergnano, "A method for reducing the energy consumption of pick-and-place industrial robots," Mechatronics, vol. 23, pp. 326-334, 2013.

[103] A. Khalid, P. Kirisci, Z. H. Khan, Z. Ghrairi, K.-D. Thoben, and J. Pannek, "Security framework for industrial collaborative robotic cyber-physical systems," Computers in Industry, vol. 97, pp. 132-145, 2018.

[104] A. Khalid, P. Kirisci, Z. Ghrairi, K-D Thoben, and J. Pannek, "Towards Implementing Safety and Security Concepts for Human-Robot Collaboration in the context of Industry 4.0," presented at the 39th International MATADOR Conference on Advanced Manufacturing, Manchester, UK, 2017.

[105] S. Nabi Jafri, J. Iqbal, H. Khan, and R. Chellali, "A unified SLAM solution using partial 3D structure," Elektronika ir Elektrotechnika, vol. 20, pp. 3-8, 2014.

[106] M. Thibaud, H. Chi, W. Zhou, and S. Piramuthu, "Internet of Things (IoT) in high-risk Environment, Health and Safety (EHS) industries: a comprehensive review," Decision Support Systems, 2018. 